\title{
ANALISIS ORIGINALITAS RESEP AYAM KESRUT SEBAGAI KULINER KHAS BANYUWANGI
}

\author{
Rudi Tri Handoko1, Firda Rachma Amalia ${ }^{2}$, Ayu Wanda Febrian ${ }^{3}$, dan Mohammad \\ Nizar Rissai ${ }^{4}$ \\ Politeknik Negeri Banyuwangi \\ rudi_rafif@poliwangi.ac.id1, firdaamalia11@poliwangi.ac.id², ayuwanda@poliwangi.ac.id³, \\ mnizarrissai.poliwangi@gmail.com ${ }^{4}$
}

\begin{abstract}
Abstrak
Banyuwangi memiliki berbagai macam kuliner khas yang memiliki citarasa beragam, salah satunya kuliner Ayam Kesrut. Kuliner ini memiliki citarasa asam, pedas dan memiliki tiga aspek gastronomic tourism yaitu aspek makanan, aspek budaya dan aspek sejarah. Penelitian ini membahas mengenai resep kuliner khas Banyuwangi yaitu Ayam Kesrut, mengetahui perbedaan resep menurut daerah masing-masing dan mencari tahu resep Ayam Kesrut yang sebenarnya. Penelitian ini dilakukan di tiga daerah yaitu Desa Kemiren, Desa Glagah dan Desa Rogojampi. Metode penelitian ini menggunakan metode Deskriptif Kualitatif. Melalui penelitian ini menunjukkan bahwa, terdapat perbedaan resep masingmasing daerah yang memiliki ciri khas sendiri. Untuk hasil originalitas resep kuliner Ayam Kesrut yaitu ayam kampung muda, cabai merah, cabai rawit, ranti dan belimbing wuluh saja dan selebihnya merupakan bumbu tambahan masing- masing daerah.
\end{abstract}

Kata kunci: Originalitas, Resep Kuliner, Kuliner khas

\begin{abstract}
Banyuwangi has a variety of culinary specialities that have a variety of flavors, one of wich is a Ayam Kesrut. This culinary has a spicy and sour taste and has three aspect of Gastronomic Tourism, namely the food aspect, the historical aspect, and cultural aspectThis research discusses the typical culinary recipes of Banyuwangi namely Ayam Kesrut, knowing the differences in recipes according to their respective regions and find out the true Ayam Kesrut recipes. This research was conducted in three regions, namely Kemiren Village, Glagah Village, Rogojampi Village. This research method uses Descriptive Qualitative method.Through this research shows that there are differences in the recipes of each region that has its own characteristics. For the results of the originality of the Ayam Kesrut culinary recipes, namely Ayam Kampung Muda, red chili, rawit pepper, ranti, blimbing wuluh and the rest are additional spices in each region.
\end{abstract}

Keywords: Originality, Culinary, Culinary Recipes

\section{PENDAHULUAN}

Pariwisata merupakan salah satu industri andalan yang harus terus ditumbuh kembangkan oleh suatu negara karena terbukti mampu menyumbang devisa secara signifikan dan mampu menarik wisatawan domestik dan mancanegara. Pariwisata adalah sebuah industri yang didalamnya terdapat komponen yang disebut 4A, yaitu atraksi wisata, aksesibilitas, amenity atau fasilitas, dan ancillary atau organisasi yang mengurus kepariwisataan, Cooper (1993 dalam prasiasa 2013). Dari keempat komponen tersebut pengeluaran cukup banyak dilakukan oleh wisatawan pada amenity yang berhubungan dengan pembelian food and beverage. Kondisi tersebut didukung data pengeluaran wisatawan dari Kementerian Pariwisata (2014), menunjukkan pengeluaran pada makanan berada di posisi kedua setelah angkutan dengan persentase 19,6 \%. Master Card Cresent Rating Muslim Shopping Travel Index 
Jurnal Manajemen Pelayanan Hotel Akademi Komunitas Manajemen Perhotelan Indonesia (Handoko, Amalia, Febrian \& Rissai, halaman 74-85) Vol 3, No 2 Edisi Desember 2019

pada tahun 2014 juga mencatat bahwa pengeluaran wisatawan di Asia Pasifik sebesar US\$26 miliyar untuk makanan dan minuman (Purnama, 2015). Peningkatan citra untuk mencapai target jumlah kunjungan wisatawan memerlukan adanya strategi pemasaran yang baik dari kuliner yang diunggulkan. Kuliner khas yang berada pada suatu destinasi pariwisata dipercaya sebagai alat promosi dan pembentuk citra destinasi yang efektif (Hjalager dan Richards, 2002). Pendekatan wisata kuliner dapat melalui aspek gastronomic tourism. Menurut Hall dan Sharples (2003) pariwisata gastronomi adalah perjalanan pengalaman ke kawasan gastronomi, untuk tujuan rekreasi atau hiburan, yang mencakup kunjungan ke produsen makanan primer dan sekunder, festival gastronomi, pameran makanan, event, pasar petani, acara memasak dan demonstrasi, mencicipi produk makanan berkualitas atau kegiatan pariwisata yang berkaitan dengan makanan.

Selain itu, sebagai tujuan wisata, bahasa Inggris juga perlu dipertimbangkan untuk mendukung keberhasilan komunikasi dengan wisatawan asing, bahasa inggris merupakan salah satu aspek penting dalam komunikasi. Bahasa Inggris ada sebagai bahasa global, oleh karena itu bahasa Inggris secara luas dianggap sebagai bahasa global (Anggayana, Nitiasih \& Budasi, 2016). Bahkan dikenal sebagai bahasa internasional (Asriyani, Suryawati \& Anggayana, 2019).

Hal ini dilakukan untuk meminimalisir kesalahan pada aspek tata bahasa atau grammar bahasa Inggris, seperti penggunaan bentuk tenses dalam kalimat (Lindawati, Asriyani \& Anggayana, 2018). Tata bahasa atau dalam bahasa Inggris disebut dengan grammar adalah seperangkat peraturan yang terdapat dalam bahasa tertentu (Lindawati, Asriyani \& Anggayana, 2019). Memungkinkan mengembangkan kompetensi komunikatif mereka dalam empat keterampilan bahasa, yaitu keterampilan menyimak, berbicara, membaca dan menulis (Asriyani, Suryawati \& Anggayana, 2019). Walaupun di Indonesia terdiri dari berbagai dialek tidak menjadi halangan (Anggayana, Budasi \& Suarnajaya, 2014). Berbahasa Inggris saat ini telah menjadi percakapan yang sering dilakukan oleh wisatawan asing (Anggayana, Budasi, \& Kusuma, 2019).

Berdasarkan observasi awal yang dilakukan oleh peneliti, Banyuwangi memiliki berbagai macam kuliner khas yang memiliki citarasa beragam, salah satunya adalah kuliner Ayam Kesrut. Kuliner ini memiliki citarasa asam pedas nan segar yang mana memiliki tiga aspek gastronomic tourism yaitu aspek makanan, aspek budaya dan aspek sejarah. Aspek yang terkandung adalah kuliner ini berbahan dasar ayam kampung muda yang direbus dengan bumbu sederhana seperti kecombrang, cabai rawit, cabai merah, bawang merah, terasi dan diberi irisan belimbing wuluh.

Kuliner ini berasal dari suku asli Banyuwangi suku Using Kemiren, dulunya ayam kesrut ini dimasak di saat-saat tertentu saja, seperti pada saat syukuran atas hasil panen yang melimpah dan apabila salah satu rumah adat suku Using berdiri. Ayam kesrut memiliki citarasa yang khas dengan bahan yang sederhana dan tidak dimiliki oleh daerah lainnya, yang mana memiliki nilai sejarah yang tinggi dan patut untuk di lestarikan dengan keaslian resepnya. Semakin tahun semakin banyak masyarakat yang tahu akan kuliner ini, tidak hanya di Desa Kemiren saja, tetapi juga merambah ke daerah lainnya, akhirnya semakin banyak versi resep yang muncul membuat wisatawan yang berkunjung untuk mencicipi kuliner ini tidak mengetahui keaslian resep kuliner ini. Misalkan ada wisatawan yang menikmati kuliner ayam kesrut di Desa Kemiren ayam kesrutnya menggunakan kecombrang dan bumbunya tidak ditumis, sedangkan di daerah Rogojampi bumbunya ditumis terlebih dahulu. Hal ini jika dibiarkan saja maka akan membuat lunturnya warisan budaya dalam segi kuliner.

\section{TINJAUAN PUSTAKA Pariwisata}

Pariwisata menurut undang undang republik Indonesia nomor 10 tahun 2009 tentang kepariwisataan adalah kegiatan perjalanan yang dilakukan seseorang atau sekelompok orang dengan mengunjungi tempat tertentu untuk tujuan rekreasi, pengembangan pribadi, atau mempelajari keunikan daya tarik wisata yang dikunjungi 
Jurnal Manajemen Pelayanan Hotel Akademi Komunitas Manajemen Perhotelan Indonesia (Handoko, Amalia, Febrian \& Rissai, halaman 74-85) Vol 3, No 2 Edisi Desember 2019

dalam waktu sementara. Menurut Buchli (dalam Wibowo, 2008) pariwisata adalah Perpindahan tempat untuk sementara waktu dan mereka yang melakukan perjalanan tersebut memperoleh pelayanan dari perusahaan-perusahaan yang bergerak dalam industri pariwisata.

Dalam pelayanan tersebut, fasilitas dan kualitas pelayanan menjadi ujung tombak dalam hal pemberian kesan baik terhadap pelayanan (Anggayana \& Sari, 2018). Dalam industri pariwisata budaya dimasukkan ke dalamnya (Redianis, Putra \& Anggayana, 2019). Sektor pariwisata mampu menyediakan ekonomi, sosial dan budaya yang bermanfaat bagi semua pelaku pariwisata stakeholders (Osin, Pibriari \& Anggayana, 2019). Menurut Spillane (1991), pariwisata adalah kegiatan melakukan perjalanan dengan tujuan mendapatkan kenikmatan, mencari kepuasan, mengetahui sesuatu, memperbaiki kesehatan, menikmati olahraga atau istirahat, menunaikan tugas, berziarah, dan lain-lain.

Tidak mengherankan bahwa industri pariwisata menjadi sektor ekonomi utama, di mana sebagian besar orang bekerja di industri pariwisata (Budasi \& Anggayana, 2019). Pada dasarnya, kemajuan suatu bangsa sangat ditentukan oleh kualitas pendidikan penduduknya (Anggayani \& Osin, 2018). Sektor pariwisata terus digalakkan karena sektor ini merupakan andalan dalam menghasilkan pendapatan masyarakat serta devisa bagi negara (Suryawati, \& Osin, 2019). Dengan berkembangnya suatu industri pariwisata akan berpengaruh kepada meningkatnya pendapatan masyarakat sekitar obyek wisata serta terciptanya lapangan kerja (Osin, Kusuma, \& Suryawati, 2019).

\section{Kuliner Khas}

Istilah kuliner di Indonesia dapat dikatakan baru terdengar gaungnya sejak tahun 2005 berkat "Wisata Kuliner", sebuah tayangan televisi yang meliput tempat-tempat makan unik atau sudah memiliki reputasi yang baik. Sejak saat itu, kata kuliner menjadi semakin populer dan menjadi sesuatu yang identik dengan mencicipi berbagai jenis makanan dan minuman (Kanal Informasi, 2019). Kuliner adalah hasil olahan yang berupa masakan berupa lauk-pauk, makanan maupun minuman. Kuliner tidak terlepas dari kegiatan masak-memasak yang erat kaitannya dengan konsumsi makanan sehari-hari. Sedangkan pengertian khas dalam kamus besar bahasa Indonesia (KBBI) adalah keistimewaan yang tidak dimiliki oleh daerah lain. Jadi, dapat diartikan bahwa pengertian kuliner khas adalah sebuah hasil olahan berupa makanan atau minuman suatu daerah yang tidak dimiliki oleh daerah lainnya.

\section{Originalitas}

Original berasal dari bahasa inggris yang jika diartikan ke dalam bahasa Indonesia yang berarti orisinal, yang dalam Kamus Besar Bahasa Indonesia (KBBI) berarti asli. Original atau bisa dikatakan dengan otentik yang artinya keaslian dari suatu daerah. Seperti contoh, jika kita mendengar tentang makanan khas kota Padang, maka yang terbesit dalam pikiran kita adalah rendang. Jadi, dapat disimpulkan bahwa rendang adalah kuliner khas asli dari padang.

\section{Pariwisata Gastronomi}

Secara historis dan etimologis, gastronomi berkaitan dengan saran dan panduan tentang apa yang harus dimakan dan diminum di mana, kapan, dengan cara apa, kemudian kombinasi ini juga dapat dipahami sebagai 'seni hidup', kepemilikan keterampilan dan pengetahuan yang berkaitan dengan makanan dan minuman dan pilihan mereka, yang meningkatkan kesenangan dan kenikmatan makan dan minum. Kesenangan seperti itu merupakan pusat pariwisata gastronomi yang berkembang sebagai bagian dari pariwisata budaya di mana pengalaman berpartisipasi dalam budaya yang berbeda adalah pusatnya (Santich, 2004).

Menurut Wolf. (2002), Wisata gastronomi adalah serangkaian kegiatan yang menampilkan makanan lokal dan budaya makanan yang unik untuk menarik wisatawan untuk menikmati makanan lokal. Beliau juga menekankan bahwa pariwisata gastronomi memotivasi wisatawan untuk menikmati makanan dan pengalaman bersantap yang tak terlupakan pada saat bersamaan. 
Menurut Messakh dan Indonesia Ministry of Tourism, 2017, konsep pariwisata gastronomi secara keseluruhan unik dan menarik karena dari berbagai aspek suatu destinasi wisata. Sebagai contoh, pariwisata gastronomi di Indonesia dipengaruhi oleh sejarah, budaya, dan makanan, yang saling mempengaruhi melalui lebih banyak lagi aspek yang dapat disajikan, bukan hanya bahanbahan saja yang terdapat pada resep masakan, tetapi terdapat juga cara mengolah bahan makanan dalam membuat suatu masakan (Lestari dan Kusrini, 2012).

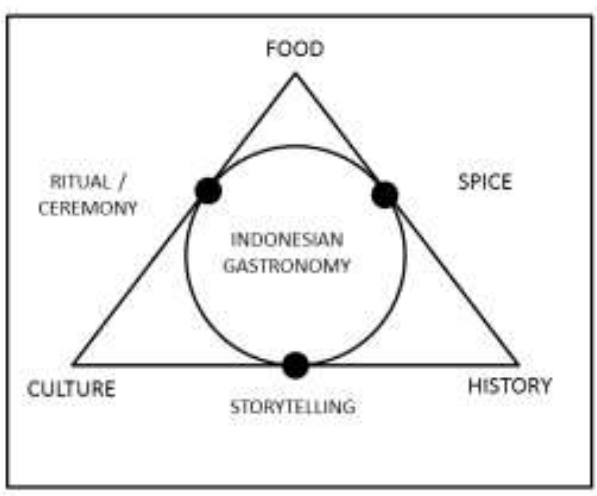

meliputi:

Aspek utama Gastronomi Indonesia

a. Food (makanan): jelas aspek sentral dari pariwisata gastronomi, dipengaruhi oleh budaya dan sejarah, melalui ritual/ceremony (upacara) dan (spices) rempah-rempah masing-masing.

b. Culture (budaya): diatur oleh makanan dan sejarah Indonesia. Storytelling (bercerita) telah membuat sejarah tetap hidup selama berabad-abad sementara ritual dan upacara yang terlibat dalam proses memasak memungkinkan makanan untuk tetap otentik dan sesuai dengan nikmat tradisional.

c. History (sejarah): pengaruh yang selalu ada pada keahlian memasak Indonesia, dibentuk oleh kedua campuran budaya abad ke-16 (termasuk pengaruh dari kerajaan Sriwijaya, Mataram dan Majapahit) serta perdagangan rempah-rempah abad ke-18. Hal ini adalah platform dalam penciptaan narasi yang kuat untuk budaya makanan Indonesia, dengan tujuan utama pencapaian keaslian, lokalitas dan kebaruan dalam pengalaman wisatawan.

\section{Soup}

Pada suatu susunan menu lengkap makanan terdapat tiga bagian yang terbagi atas appetizer (hidangan pembuka), maincourse (hidangan utama), dan dessert (hidangan penutup). Appetizer (hidangan pembuka) merupakan hidangan yang disajikan sebelum maincourse (hidangan utama) yang disajikan bertujuan untuk membangkitkan nafsu makan, porsinya pun tidak terlalu besar dan cenderung bersifat a la minute atau proses pembuatannya tidak memakan waktu lama. Sedangkan soup (hidangan berkuah) adalah bahan makanan yang terbuat dari sayuran, ikan, daging dan unggas, yang berkuah cair atau kental yang diberi rasa atau bumbu. Dalam menu soup, terdapat beberapa fungsi untuk membangkitkan selera makan, untuk menetralkan rasa tajam dari cold appetizer atau memasuki hidangan berikutnya. (Akparindo, 2019).

\section{Resep Masakan}

Resep masakan merupakan panduan bagi seseorang dalam mengolah bahan makanan menjadi hidangan yang dapat disajikan, bukan hanya bahan-bahan saja yang terdapat pada resep masakan, tetapi terdapat juga cara mengolah bahan makanan dalam membuat suatu masakan (Lestari dan Kusrini, 2012).

\section{Kuliner Ayam Kesrut}

Menurut Febrian (2019) Ayam Kesrut merupakan kuliner khas Banyuwangi. Orang Kemiren menamai Uyah Asem, karena jaman dulu masyarakat Kemiren tidak pernah membeli bahan masakan, hanya garam saja yang beli, karena kita menanamnya sendiri, jadi kalau mau masak di sawah langsung mengambil bahan-bahannya di kebun langsung dihaluskan kemudian dimasukan ke dalam kuah Ayam Kesurt. Ayam Kesrut yang berbahan dasar ayam kampung muda diberi bumbu sederhana seperti bawang merah, cabai merah, cabai rawit, sedikit terasi dan diberi potongan kecombrang. Dulunya Ayam Kesrut ini dimasak pada saat - saat tertentu saja, seperti pada saat berdirinya rumah adat 
Jurnal Manajemen Pelayanan Hotel Akademi Komunitas Manajemen Perhotelan Indonesia (Handoko, Amalia, Febrian \& Rissai, halaman 74-85) Vol 3, No 2 Edisi Desember 2019

suku Using dan pada saat panen raya melimpah.

\section{METODE PENELITIAN}

Penelitian ini dimulai di desa Kemiren kecamatan Glagah kabupaten Banyuwangi. Tempat ini dipilih karena selain terdapat suku asli Banyuwangi yaitu suku Using, juga memiliki sejarah kuat akan kemunculan kuliner khas Banyuwangi yaitu Ayam Kesrut ini. Kemudian dilanjutkan di daerah-daerah di Kabupaten Banyuwangi yang terindikasi memiliki resep kuliner Ayam Kesrut dengan versi yang berbeda.

Metode penelitian ini menggunakan metode deskriptif kualitatif, pendekatan kualitatif merupakan metode-metode untuk mengeksplorasi dan memahami makna yang dianggap berasal dari masalah sosial atau kemanusiaan. Proses penelitian kualitatif ini melibatkan upaya-upaya penting, seperti mengajukan pertanyaan-pertanyaan dan prosedur-prosedur, mengumpulkan data yang spesifik dari para partisipan, menganalisis data secara induktif mulai dari tema-tema yang khusus ke tema-tema yang umum, dan menafsirkan makna data. Penelitian ini menggunakan teknik pengumpulan data yaitu observasi, dokumentasi dan wawancara.

\section{HASIL DAN PEMBAHASAN}

Banyuwangi memiliki berbagai macam kuliner khas yang memiliki cita rasa beragam, mulai dari kuliner dengan citarasa manis sampai yang pedas, salah satunya adalah kuliner Ayam Kesrut atau masyarakat Kemiren menyebutnya Uyah Asem. Kuliner ini sudah menjadi kuliner yang sangat digemari oleh masyarakat Banyuwangi. Menurut Ibu Holilah (warga suku Using Kemiren) resep dari Ayam Kesrut ini cukup sederhana dan mudah dijumpai di lingkungan sekitar, seperti cabai merah, cabai rawit, kemiri, bawang merah, laos, daun salam, kunyit dan tunas dari pohon kecombrang atau orang Banyuwangi menyebutnya lucu. Cara memasaknya pun cukup mudah, yaitu pertama ayam kampung muda yang sudah dipotong dan dibersihkan direbus sampai matang, kemudian direbus kembali dengan air yang berbeda, hal ini dilakukan agar ayam benar-benar bersih dan matang, setelah itu haluskan semua bumbu dan masukkan kedalam rebusan ayam, setelah itu masukkan daun salam dan potongan tunas kecombrang untuk memunculkan citarasa yang khas.

Menurut Bapak Sucipto (Generasi ke -6 Barong Sapujagad Kemiren), kuliner ini sudah ada sejak 200 tahun yang lalu. Pada masa itu kuliner ini dimasak pada saat-saat tertentu saja, seperti saat syukuran atas panen melimpah, berdirinya rumah adat Banyuwangi, dan pada saat mendirikan pondok di sawah, pada masa itu orang-orang bekerja secara gotong-royong (ngersoyo), setelah bekerja secara gotong-royong, mereka akan disuguhkan makanan-makanan yang membuat rasa lelah hilang seperti ketan urap (ketan diberi parutan kelapa dan bubuk kacang) dan tentunya Uyah Asem. Mereka akan senang jika menikmati suguhan secara bersama dan dengan diiringi musik Angklung Paglak (alat musik tradisional yang terbuat dari bambu dan dimainkan diatas Paglak/pondok).

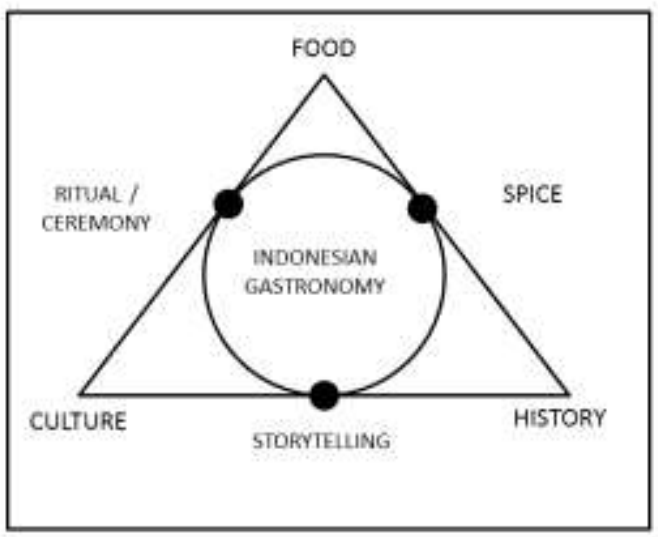

meliputi:

Aspek utama Gastronomi Indonesia

a. Food (makanan): jelas aspek sentral dari pariwisata gastronomi, dipengaruhi oleh budaya dan sejarah, melalui ritual/ceremony (upacara) dan (spices) rempah-rempah masing-masing.

b. Culture (budaya): diatur oleh makanan dan sejarah Indonesia. Storytelling (bercerita) telah membuat sejarah tetap hidup selama berabad-abad.

c. History (sejarah): pengaruh yang selalu ada pada keahlian memasak Indonesia, dibentuk oleh kedua campuran budaya 
abad ke-16 (termasuk pengaruh dari kerajaan Sriwijaya, Mataram dan Majapahit) serta perdagangan rempah-rempah abad ke-18. Hal ini adalah platform dalam penciptaan narasi yang kuat untuk budaya makanan Indonesia, dengan tujuan utama pencapaian keaslian, lokalitas dan kebaruan dalam pengalaman wisatawan.

Dalam penelitian ini, peneliti menggunakan konsep segitiga Gastronomi Indonesia yang terdiri dari tiga aspek yaitu, aspek Sejarah, aspek Budaya, dan Aspek Makanan. Kemudian membahas tentang originalitas resep kuliner Ayam Kesrut khas Banyuwangi dalam aspek makanan. Berdasarkan dari hasil penelitian, kuliner Ayam Kesrut ini juga memiiki nilai budaya yang terkandung. Dulunya, Ayam Kesrut dimasak pada saat $\mathrm{Ngersoyo} \mathrm{saja,} \mathrm{tetapi} \mathrm{semakin} \mathrm{tahun}$ kuliner ini dijadikan sebagai masakan seharihari oleh masyarakat Banyuwangi.

Originalitas yang dimaksud disini adalah bumbu-bumbu pokok yang harus ada di dalam masakan Ayam Kesrut dan jika bumbubumbu tersebut ada, maka bisa dikatakan bumbu pokok Ayam Kesrut. Kemudian jika ada bumbu-bumbu yang lain, merupakan bumbu tambahan versi daerah masing-masing. Berikut merupakan hasil penelitian resep masakan Ayam Kesrut di beberapa daerah yang sudah ditambahkan beberapa bumbu tambahan.

\section{A. Analisis Resep Ayam Kesrut Versi Desa Kemiren.}

Di Desa Kemiren, Ayam Kesrut disebut Uyah Asem yang berarti garam dan asam. Hal ini dikarenakan pada zaman dahulu masakan ini mempunyai bumbu yang sederhana. Menurut Bapak Sucipto (generasi ke-6 Barong Sapujagad Kemiren), waktu itu orang memasak Ayam Kesrut hanya bermodalkan garam dan daun wadung saja, tanpa tambahan bumbu lainnya. Menurut Bapak Sucipto (generasi ke-6 Barong Sapujagad Kemiren), waktu itu orang memasak Ayam Kesrut hanya bermodalkan garam dan daun wadung saja, tanpa tambahan bumbu lainnya. Ayam Kesrut ini dimasak pada saat mereka menjaga sawahnya dari hama selama 7 bulan, sampai padi siap untuk dipanen, selain itu dimasak pada saat sawah akan panen, mereka akan bergotong-royong
(Ngersoyo) untuk memanen padi tersebut dan dimasakkan Ayam Kesrut ini, selain pada saat memanen sawah, Ayam Kesrut atau Uyah Asem ini dimasak pada saat mendirikan pondok di sawah dan mendirikan rumah adat, karena pada zaman dulu jika ada masyarakat Desa Kemiren yang akan pindah rumah, mereka tidak membongkar seluruhnya tetapi memindahkan rumah tersebut dari tempat asal ke tempat barunya, hal ini membutuhkan tenaga yang banyak dan tentunya orang-orang yang sudah bergotong-royong akan senang jika disuguhkan makanan Ayam Kerut ini.

Terdapat sisi lain dari arti Uyah Asem itu sendiri, menurut Bapak Herman (Pemilik Warung Pesantogan Kemangi) arti dari kata Uyah Asem adalah umyah-umyah myakne ayem (rumah tangganya dalam keadaan tentram dan damai). Hal ini berkaitan dengan masyarakat Desa Kemiren yang akan berpindah rumah, berharap akan lebih tentram lagi daripada rumah yang sebelumnya. Sebagaimana kutipan berikut.

"kalau Uyah Asem disini ada pada saat Ngersoyo atau bergotong-royong untuk mendirikan rumah, jika ada orang yang masak Uyah Asem berarti ada orang yang sedang mendirikan rumah. Karena pada jaman dulu kalau ada orang yang pindah rumah itu tidak dibongkar semua mas, tetapi hanya sebagian dan sebagian lagi digotong rame-rame mas. Bisa dikatakan Uyah Asem sebagai simbol agar harapan orang yang baru pindah rumah lebih tenang dan damai dengan rumah barunya." (wawancara dengan Bapak Herman, Juli 2019)

Resep Ayam Kesrut mengalami variasi dari waktu ke waktu, dan semakin kompleks. Pada saat ini resep Ayam Kesrut di Desa Kemiren mengalami variasi dari resep sebelumnya. Menurut Ibu Holila (warga asli Desa Kemiren), konsep Gastronomi Indonesia dari segi Makanan atau resep Ayam Kesrut dalam tabel sebagai berikut. 


\begin{tabular}{ll}
\hline \multicolumn{1}{c}{ Nama Bahan } & \multicolumn{1}{c}{ Jumlah } \\
\hline Ayam Kampung & 1 Ekor \\
Muda & 2 Buah \\
Cabe Merah & 20 Buah \\
Kunyit & Secukupnya \\
Bawang Merah & 5 Siung \\
Bawang Putih & 2 Siung \\
Terasi & Secukupnya \\
Ranti & 1 Buah \\
Daun Salam & 3 Lembar \\
Kecombrang & 1 Ruas \\
Sayur Buncis & Sesuai Selera \\
\hline
\end{tabular}

Untuk pengolahannya pun cukup sederhana, pertama ayam kampung muda yang sudah dibersihkan kemudian dipotong menjadi beberapa bagian. Menurut Ibu Holila (warga asli Desa Kemiren) pemilihan ayam kampung yang masih muda (pethetheng) bertujuan agar daging yang dihasilkan masih empuk dan terasa ada manis-manisnya. Setelah itu direbus sampai matang dan diberi irisan kecombrang agar bau khas dari kecombrang tersebut keluar, Pak Sucipto juga menambahkan untuk lucu atau kecombrang harus yang masih segar baru di ambil dari pohonnya, hal ini bertujuan untuk mempertahankan kesegaran dari kecombrang itu sendiri. Sembari menunggu ayam matang, bumbu-bumbu diatas dihaluskan kecuali daun salam dan alat untuk menghaluskan pun harus menggunakan ulegan, tidak boleh menggunakan penghalus otomatis atau blender karena akan mempengaruhi rasa dari Ayam Kesrut itu sendiri. Setelah halus dan ayam sudah matang, buang air rebusan tersebut kemudian rebus kembali, hal ini bertujuan agar kotoran dari ayam tersebut benar-benar hilang, tunggu hingga mendidih kembali kemudian masukkan bumbu yang sudah dihaluskan tadi ke dalam rebusan ayam, kemudian tambahkan garam secukupnya lalu sajikan.
Jadi dapat disimpulkan bahwa aspek makanan dari konsep Gastronomi Indonesia yang dimiliki kuliner Ayam Kesrut versi desa Kemiren ini memiliki bumbu-bumbu yang sudah mengalami inovasi dari resep jaman nenek moyang dulu. Kuliner ini bercitarasa asam yang dihasilkan dari ranti dan lucu, untuk ciri khas warna dari kuliner ini adalah bening sedikit kuning yang dihasilkan dari kunyit.

\section{B. Analisis Resep Ayam Kesrut Versi Desa Glagah}

Di Desa Glagah kuliner Ayam Kesrut merupakan kuliner yang sangat digemari oleh masyarakat Desa Glagah, hampir setiap hari terdapat masyarakat yang memasak kuliner ini. Sama halnya di Desa Kemiren, mereka menyebut Ayam Kesrut adalah Uyah Asem, dulunya Uyah Asem dimasak pada saat acara syukuran untuk rumah yang baru selesai dibangun. Tidak hanya itu, Uyah Asem dimasak pada saat acara nikahan atau hajatan lainnya dan masakan ini diperuntukkan untuk para pelabot (orang-orang yang membantu kelancaran hajatan). Seiring berjalannya waktu, masakan ini menjadi masakan seharihari oleh masyarakat Desa Glagah, dan tidak dimasak pada saat syukuran rumah saja.

Untuk bumbu dan bahan-bahan yang dibutuhkan untuk memasak Ayam Kesrut di Desa Glagah sangat mudah dan lebih sederhana dari Desa Kemiren. Menurut ibu Sumiyati (warga asli Desa Glagah) bumbu dan bahan yang dibutuhkan yang mewakili aspek makanan dari konsep Gastronomi Indonesia dalam bentuk tabel dan gambar sebagai berikut.

\begin{tabular}{|c|c|}
\hline Bahan & Jumlah \\
\hline $\begin{array}{l}\text { Ayam Kampung } \\
\text { Muda } \\
\text { Cabe Merah }\end{array}$ & $\begin{array}{l}1 \text { Ekor } \\
5 \text { Buah }\end{array}$ \\
\hline Cabe Rawit & 10 Buah \\
\hline Belimbing Wuluh & 8 Buah \\
\hline Ranti & 4 Buah \\
\hline Daun Wadhung & 5 Lembar \\
\hline
\end{tabular}


Berdasarkan dan tabel di atas, dapat diketahui bahwa bumbu-bumbu yang dibutuhkan untuk memasak Ayam Kesrut Dersi desa Glagah sangat sederhana yaitu cabai besar, cabai rawit, ranti, belimbing wuluh dan juga daun wadhung. Untuk cara pengolahannya cukup mudah, pertama rebus ayam kampung muda yang sudah dibersihkan dan dipotong menjadi beberapa bagian, sembari menunggu matang, haluskan cabai merah, cabai rawit dan ranti menggunakan ulegan setelah halus, iris halus daun wadhung dan belimbing wuluh memarkan, hal ini bertujuan agar air yang berasal dari belimbing wuluh keluar. Setelah ayam matang, buang air rebusan ayam dan rebus kembali ayam tersebut. Tidak menunggu mendidih, masukkan bumbu yang dihaluskan tadi, tambahkan potongan daun wadhung dan belimbing wuluh kedalam rebusan ayam tersebut. Setelah mendidih, masukkan garam agar rasa dari Ayam Kesrut ini seimbang kemudian sajikan.

Perbedaan yang terdapat pada kuliner Ayam Kesrut di Desa Glagah dengan Desa Kemiren, terletak pada cara pengolahan dan juga bumbu-bumbu yang dibutuhkan lebih sederhana. Ibu Sumiyati memberikan tanggapan tentang terjadinya perbedaan resep ini, dikarenakan perbedaan daerah dan perbedaan selera masing-masing orang. Untuk peran pemerintah dalam mengelola kuliner ini, pemerintah desa pernah mengadakan lomba memasak Ayam kesrut untuk memeriahkan hari kemerdekaan Indonesia pada tahun lalu. Hal ini bertujuan untuk upaya mempertahankan warisan leluhur dari segi kuliner. Jadi dapat disimpulkan bahwa aspek makanan dari konsep Gastronomi Indonesia yang dimiliki kuliner Ayam Kesrut versi Desa Glagah memiliki resep yang lebih sederhana dari desa Kemiren, tetapi memiliki citarasa khas yang sama yaitu asam segar dan juga pedas. Untuk ciri khas warna bening kemerahan.

\section{Analisis Resep Ayam Kesrut Versi Desa Rogojampi}

Kuliner Ayam Kesrut di Desa Rogojampi memiliki sejarah yang berbeda dengan kuliner Ayam Kesrut di daerah sebelumnya. Jika di Kemiren, Ayam Kesrut dulunya dimasak pada saat syukuran atas panen sawah melimpah, dan pada saat berdirinya rumah adat suku Using, maka berbeda halnya di Desa Rogojampi ini. Menurut Mbah Nasiah (warga asli Desa Rogojampi) kuliner Ayam Kesrut melambangkan kesederhanaan dan menjadi simbol masyarakat Banyuwangi yang suka dengan makanan pedas dan segar. Untuk resep Ayam Kesrut di Desa Rogojampi ini lebih bervariasi daripada di Desa Kemiren dan Desa Glagah. Menurut Mbah Nasiah aspek makanan dari konsep Gastronomi Indonesia yang terkandung pada kuliner Ayam Kesrut dalam tabel dan gambar sebagai berikut.

\begin{tabular}{ll}
\hline \multicolumn{1}{c}{ Nama Bahan } & \multicolumn{1}{c}{ Jumlah } \\
\hline $\begin{array}{l}\text { Ayam Kampung } \\
\text { Muda }\end{array}$ & 1 Ekor \\
Cabe Merah & 6 Buah \\
Cabe Rawit & 10 Buah \\
Belimbing Wuluh & 10 Buah \\
Ranti & 2 Buah \\
Daun Bawang & Secukupnya \\
Bawang Merah & 7 siung \\
Terasi & Secukupnya \\
\hline
\end{tabular}

Berdasarkan tabel di atas dapat dilihat bahwa bumbu yang dibutuhkan untuk memasak Ayam Kesrut ini sedikit lebih banyak daripada resep di Desa Kemiren dan Desa Glagah. Hal ini disebabkan karena selera masyarakat Desa Glagah itu sendiri. Bumbubumbu tersebut diantaranya cabai merah, cabai rawit, ranti, belimbing wuluh, daun bawang dan sedikit terasi. Adapun cara pengolahannya yang pertama adalah rebus ayam kampung muda yang sudah dibersihkan terlebih dahulu, yang kedua iris tipis bawang merah lalu goreng hingga kecoklatan dan aroma khas keluar, selain bawang merah potong juga daun bawang dengan panjang kira-kira $2 \mathrm{~cm}$ lalu goreng hingga matang dan aroma khas keluar.

Cita rasa yang ditimbulkan dari Ayam Kesrut di Desa Rogojampi ini adalah segar asam pedas dan sedikit manis. Hal ini disebabkan karena 
takaran seasoning dari garam dan gula sudah sesuai. Untuk warna khas dari Ayam Kesrut di Desa Rogojampi cenderung keruh dan berwarna merah yang ditimbulkan dari cabai merah besar. Perbedaan resep kuliner Ayam Kesrut di Desa Rogojampi dengan Desa Kemiren dan Glagah terletak pada resep yang dibutuhkan. Jika di Desa Rogojampi ada bumbu tambahan yaitu bawang merah dan daun bawang yang dipotong. Selain itu, perbedaan yang terjadi pada resep Ayam Kesrut ini adalah pengolahannya, jika di Desa Kemiren dan Desa Glagah bumbunya tidak ditumis, maka di Desa Rogojampi ditumis terlebih dahulu hingga matang dan tercium bau harum dari bumbu tersebut. Sebagaimana pernyataan berikut.

"enak yang ini mas, karena disini menggunakan bawang merah dan daun bawang, selain itu juga bumbu yang sudah dihaluskan di tumis terlebih dahulu jadi untuk bumbunya sangat sedep mas. Perbedaan ini juga muncul karena selera pembuatnya masing-masing mas. Dari segi rasa juga enak disini karena bumbunya lebih lengkap mas, kebanyakan masyarakat Rogojampi masak Ayam Kesrutnya ya kaya gini ini mas." (wawancara dengan Mbah Nasiah, Juli 2019)

Dari pernyataan di atas dapat dilihat bahwa perbedaan dari kuliner Ayam Kesrut ini sangat mencolok dari segi bumbu dan cara pengolahannya. Untuk peran dari masyarakat mengelola kuliner ini adalah setiap orang masyarakat memasak kuliner ini sebagai masakan sehari-hari.

Jadi dapat disimpulkan bahwa aspek makanan dari konsep Gastronomi Indonesia yang dimiliki kuliner Ayam Kesrut versi Desa Rogojampi, lebih bervariasi daripada resep Ayam Kesrut yang ada di Desa Kemiren dan Desa Glagah. Dari segi citarasa yang ditimbulkan cenderung asam dan rasa khas dari daun bawang. Untuk segi warna lebih keruh dan sedikit ada minyak yan keluar dari ayam dan hasil dari tumisan bumbu yang sudah dihaluskan tadi.

\section{Analisis Resep Ayam Kesrut Secara Original}

Berdasarkan hasil penelitian di tiga daerah antara lain Desa Kemiren, Desa Glagah dan Desa Rogojampi, memiliki ciri khas Ayam Kesrut yang berbeda. Hal ini disebabkan karena perbedaan wilayah dan selera dari masing-masing pembuatnya. Selain itu juga berasal dari bahan baku yang tidak ada di setiap daerah seperti halnya lucu, pohon lucu atau kecombrang jarang ditemui di daerah lain, tetapi di daerah Desa Kemiren pohon ini sangat mudah dijumpai di pekarangan atau di halaman belakang rumah warga. Hal ini membuat lucu sebagai ciri khas dari Desa Kemiren.

Di dalam resep kuliner Ayam Kesrut terdapat bumbu atau bahan pokok yang harus ada pada saat memasak kuliner tersebut. Berdasarkan hasil penelitian yang dilakukan oleh peneliti di tiga daerah yaitu Desa Kemiren, Desa Glagah dan Desa Rogojampi dapat disimpulkan resep atau bahan yang harus ada diantara lain pada tabel komparasi dan gambar berikut.

\begin{tabular}{|c|c|c|c|c|}
\hline $\begin{array}{l}N \\
0\end{array}$ & $\begin{array}{l}\text { Nama } \\
\text { Bahan }\end{array}$ & $\begin{array}{c}\text { Desa } \\
\text { Kemire } \\
n\end{array}$ & $\begin{array}{c}\text { Desa } \\
\text { Glaga } \\
\mathrm{h}\end{array}$ & $\begin{array}{c}\text { Desa } \\
\text { Rogojamp } \\
\text { i }\end{array}$ \\
\hline 1. & $\begin{array}{l}\text { Ayam } \\
\text { Kampun } \\
\text { g Muda }\end{array}$ & $\sqrt{ }$ & $\sqrt{ }$ & $\sqrt{ }$ \\
\hline 2. & $\begin{array}{l}\text { Cabai } \\
\text { Merah }\end{array}$ & $\sqrt{ }$ & $\sqrt{ }$ & $\sqrt{ }$ \\
\hline 3. & $\begin{array}{l}\text { Cabai } \\
\text { Rawit }\end{array}$ & $\sqrt{ }$ & $\sqrt{ }$ & $\sqrt{ }$ \\
\hline 4. & Kunyit & $\sqrt{ }$ & - & - \\
\hline 5. & $\begin{array}{l}\text { Bawang } \\
\text { Merah }\end{array}$ & $\sqrt{ }$ & - & $\sqrt{ }$ \\
\hline 6. & $\begin{array}{l}\text { Bawang } \\
\text { Putih }\end{array}$ & $\sqrt{ }$ & - & - \\
\hline 7. & Terasi & $\sqrt{ }$ & - & $\sqrt{ }$ \\
\hline 8. & Ranti & $\sqrt{ }$ & $\sqrt{ }$ & $\sqrt{ }$ \\
\hline 9. & $\begin{array}{l}\text { Daun } \\
\text { Salam }\end{array}$ & $\sqrt{ }$ & - & - \\
\hline
\end{tabular}


Jurnal Manajemen Pelayanan Hotel Akademi Komunitas Manajemen Perhotelan Indonesia (Handoko, Amalia, Febrian \& Rissai, halaman 74-85) Vol 3, No 2 Edisi Desember 2019

\begin{tabular}{|c|c|c|c|c|}
\hline 10 & $\begin{array}{l}\text { Kecombr } \\
\text { ang }\end{array}$ & $\sqrt{ }$ & - & - \\
\hline 11 & $\begin{array}{l}\text { Sayur } \\
\text { Buncis }\end{array}$ & $\sqrt{ }$ & - & - \\
\hline 12 & $\begin{array}{l}\text { Belimbin } \\
\text { g Wuluh }\end{array}$ & - & $\sqrt{ }$ & $\sqrt{ }$ \\
\hline 13 & $\begin{array}{l}\text { Daun } \\
\text { Wadhun } \\
\text { q }\end{array}$ & - & $\sqrt{ }$ & - \\
\hline 14 & $\begin{array}{l}\text { Daun } \\
\text { Bawang }\end{array}$ & - & - & $\sqrt{ }$ \\
\hline
\end{tabular}

Berdasarkan tabel komparasi di atas dapat dilihat bahwa resep pokok yang harus ada pada Ayam Kesrut diantara lain ayam kampung muda (pethetheng), cabai merah, cabai rawit, terasi, ranti dan belimbing wuluh. Untuk cara pengolahannya pun tidak berbeda jauh dengan pengolahan sebelumnya, pertama ayam kampung muda yang sudah dibersihkan direbus hingga matang, setelah mendidih bersihkan kotoran yang ada pada rebusan ayam tersebut dan jangan dibuang air rebusannya. Hal ini dilakukan untuk mempertahankan kaldu yang dikeluarkan dari ayam kampung tersebut. Kemudian haluskan bumbu yang sudah ada dengan menggunakan ulegan, setelah bumbu halus, masukkan ke dalam rebusan ayam kemudian lakukan seasoning agar rasa yang ditimbulkan seimbang dan sesuai yang diharapkan. Setelah itu sajikan.

Jadi dapat disimpulkan bahwa, aspek makanan dari konsep Gastronomi Indonesia yang dimiliki resep kuliner Ayam Kesrut secara original, adalah ayam kampung muda, cabai merah, cabai rawit dan belimbing wuluh saja. Jika ada bahan lainnya, itu merupakan bahan tambahan dari versi masing-masing daerah. Untuk pengolahannya pun cukup mudah. Pertama, ayam kampung yang sudah dibersihkan direbus hingga matang, kedua haluskan cabai merah, cabai rawit, dan ranti. Ketiga potong belimbing wuluh dan memarkan, hal ini dilakukan agar air dari belimbing wuluh keluar dan menimbulkan cita rasa asam. Setelah ayam kampung matang, bersihkan sisa-sisa kotoran yang keluar dan jangan dibuang karena akan mengurangi kaldu yang keluar dari ayam tersebut. Kemudian masukkan bumbu yang sudah dihaluskan dan juga potongan belimbing wuluh ke dalam air rebusan ayam. Tambahkan sedikit garam dan gula sebagai penyeimbang rasa.

\section{PENUTUP}

Originalitas resep Ayam Kesrut ini mengacu pada konsep Segitiga Gastronomi Indonesia, yang terdiri dari history (sejarah), culture (budaya) dan food (makanan) dan kuliner Ayam Kesrut ini memiliki ketiganya. Penelitian ini membahas tentang aspek makanan dari konsep Segitiga Gastronomi Indonesia yang dimiliki oleh kuliner Ayam Kesrut. Adapun aspek tersebut dapat dijelaskan dalam tabel berikut.

\begin{tabular}{ll}
\multicolumn{1}{c}{ Nama Bahan } & \multicolumn{1}{c}{ Jumlah } \\
\hline $\begin{array}{l}\text { Ayam Kampung } \\
\text { muda }\end{array}$ & 1 ekor \\
Cabai merah & $5 \mathrm{biji}$ \\
Cabai rawit & $10 \mathrm{bii}$ \\
Ranti & $3 \mathrm{biji}$ \\
Belimbing wuluh & $5 \mathrm{biji}$
\end{tabular}

Berdasarkan tabel di atas dapat dilihat bahwa resep pokok yang terdapat pada ketiga daerah, harus ada pada Ayam Kesrut diantara lain ayam kampung muda (pethetheng), cabai merah, cabai rawit, terasi, ranti dan belimbing wuluh. Untuk cara pengolahannya pun tidak berbeda jauh dengan pengolahan sebelumnya, pertama ayam kampung muda yang sudah dibersihkan direbus hingga matang, setelah mendidih bersihkan kotoran yang ada pada rebusan ayam tersebut dan jangan dibuang air rebusannya. Hal ini dilakukan untuk mempertahankan kaldu yang dikeluarkan dari ayam kampung tersebut. Kemudian haluskan bumbu yang sudah ada dengan menggunakan ulegan, setelah bumbu halus, masukkan ke dalam rebusan ayam kemudian lakukan seasoning agar rasa yang ditimbulkan seimbang dan sesuai yang diharapkan. Setelah itu sajikan. Jika terdapat bumbu tambahan lainnya, maka itu bisa dikatakan variasi dari masing-masing daerah. 
Jurnal Manajemen Pelayanan Hotel Akademi Komunitas Manajemen Perhotelan Indonesia (Handoko, Amalia, Febrian \& Rissai, halaman 74-85) Vol 3, No 2 Edisi Desember 2019

\section{UCAPAN TERIMAKASIH}

Selama penulisan penelitian ini, penulis mendapatkan banyak bantuan dari berbagai pihak. Oleh karena itu penulis ingin menyampaikan rasa terima kasih yang sedalam - dalamnya kepada Direktorat Penelitian dan Pengabdian kepada Masyarakat dan DIRJEN DIKTI yang telah memberikan kesempatan moril dan materiil, Direktur Polieknik Negeri Banyuwangi dan Ketua P3M Politeknik Negeri Banyuwangi yang telah memberikan kesempatan kepada penulis untuk melakukan penelitian ini serta membantu proses birokrasi pada instansi instansi terkait, serta seluruh pihak yang sudah membantu kelancaran penyelesaian penelian ini.

\section{DAFTAR RUJUKAN}

Anggayana, I. A., Budasi, I. G., \& Kusuma, I. W. (2019). Social Dialectology Study of Phonology in Knowing English Student Speaking Ability. (P. Robertson, Ed.) The Asian EFL Journal, 25(5.2), 225-244.

Anggayana, I. W. A., \& Sari, N. L. K. J. P. (2018). Kemampuan Berbicara Bahasa Inggris Mahasiswa Akomodasi Perhotelan: sebuah Kajian Fonologi. Jurnal Manajemen Pelayanan Hotel, 1(1), 8-14.

Anggayana, I. W. A., Budasi, I. G., Lin, D. A., \& Suarnajaya, I. W. (2014). Affixation of bugbug dialect: A Descriptive Study. Jurnal Pendidikan Bahasa Inggris undiksha, 1(1).

ANGGAYANA, I. W. A., NITIASIH, D. P. K., BUDASI, D. I. G., \& APPLIN, M. E. D. (2016). Developing English For Specific Purposes Course Materials for Art Shop Attendants and Street Vendors. Jurnal Pendidikan Bahasa Inggris Indonesia, 4(1).

Anggayani, N. W., \& Osin, R. F. (2018). Pengaruh Service Performance Terhadap Nilai Sekolah Kepuasan Dan Loyalitas Pelajar Pada Smk Pariwisata Triatma Jaya Tabanan. Jurnal Manajemen Pelayanan Hotel, 1(1), 2835.

Asriyani, R., Suryawati, D. A., \& Anggayana, I. W. A. (2019). PENERAPAN TEKNIK
ROLE PLAY DALAM MENINGKATKAN KOMPETENSI BERBICARA BAHASA INGGRIS SISWA KELAS SEBELAS TERHADAP KEANEKARAGAMAN PERSONALITY TYPES DI SMK PARIWISATA TRIATMA JAYA BADUNG. LITERA: Jurnal Litera Bahasa Dan Sastra, 5(2).

Asriyani, R., Suryawati, D. A., \& Anggayana, I. W. A. (2019, August). USING ROLE PLAY TECHNIQUES IN IMPROVING ENGLISH SPEAKING COMPETENCY ON THE PERSONALITY TYPES. In International Conference on Cultural Studies (Vol. 2, pp. 44-48).

Budasi, I. G., \& Anggayana, I. A. (2019). Developing English for Housekeeping Materials for Students of Sun Lingua College Singaraja-Bali. The Asian EFL Journal, 23(6.2), 164-179.

Febrian, A. W, Wijaya, J. A. C dan Amalia, F. R. 2019. Analisis Brand Identity Kuliner Di Kabupaten Banyuwangi Dengan Menggunakan Konsep Gastronomic Tourism. The International Journal of Applied Business. 3(1)

Hall, C. M, Sharples, L., Mitchell, R., Macions, N. dan Cambourne, B. (2003). Food Tourism around the World: Development, Management and Markets.[skripsi] Boston, MA: Butterworth-Heinemann.

Lindawati, N. P., Asriyani, R., \& Anggayana, I. W. A. (2018). KEMAMPUAN MENULIS KARANGAN DIALOG MELALUI MODEL PEMBELAJARAN KOOPERATIF TIPE THINK-PAIR-SHARE PADA MAHASISWA JURUSAN TATA HIDANGAN DI AKADEMI KOMUNITAS MANAJEMEN PERHOTELAN INDONESIA. SINTESA.

Lindawati, N. P., Asriyani, R., \& Anggayana, I. W. A. (2019). MODEL KOOPERATIF THINK-PAIR-SHARE

MENINGKATKAN KEMAMPUAN MENULIS KARANGAN DIALOG BAHASA INGGRIS MAHASISWA AKADEMI KOMUNITAS MANAJEMEN PERHOTELAN INDONESIA. LITERA: Jurnal Litera Bahasa Dan Sastra, 4(1).

Messakh, V.D., dan Indonesia Ministry of Tourism. 
Osin, R. F., Kusuma, I. R. W., \& Suryawati, D. A. (2019). STRATEGI PENGEMBANGAN OBJEK WISATA KAMPUNG TRADISIONAL BENA KABUPATEN NGADA-FLORES NUSA TENGGARA TIMUR (NTT). Jurnal Ekonomi dan Pariwisata, 14(1).

Osin, R. F., Pibriari, N. P. W., \& Anggayana, I. W. A. (2019, August). BALINESE WOMEN IN SPA TOURISM IN BADUNG REGENCY. In International Conference on Cultural Studies (Vol. 2, pp. 35-38).

Prasiasa, D. 2013. Destinasi pariwisata berbasis masyarakat. Jakarta : Salemba Humanika.

Purnama, H. 2015. Pengeluaran Wisatawan Muslim Berpusat di Asia Pasifik. [diakses pada 2019 mar 01]. Tersedia pada http://venuemagz.com/feature/pengeluar an-wisatawan-muslim-berpusat-di-asiapasifik/.

Redianis, N. L., Putra, A. A. B. M. A., \& Anggayana, I. W. A. (2019, August). EFFECT OF CULTURE ON BALINESE LANGUAGE USED BY EMPLOYEE HOTELS FOR FOREIGN TRAVELERS IN THE SOCIOLINGUISTIC PERSPECTIVE. In International Conference on Cultural Studies (Vol. 2, pp. 39-43).

Santich, B. 2004. The study of gastronomy and its relevance to hospitality education and training. International Journal of Hospitality Management, 23, 15-24.

Spillane, J.J. 1991. Ekonomi Pariwisata:Sejarah dan Prospekny

Suryawati, D. A., \& Osin, R. F. (2019). Analisis Menu untuk Menentukan Strategi Bauran Pemasaran pada Bunut Café di Hotel White Rose Legian Kuta. Jurnal Manajemen Pelayanan Hotel, 3(1), 2935.

Undang-Undang Nomor 10 Tahun 2009 tentang Kepariwisataan.

Wolf, E. 2002. Culinary Tourism : A Tasty Economic Proposition. [Diunduh 2019 mar 15 ] Tersedia pada https://www.worldfoodtravel.org. 